\title{
La máquina antropológica como máquina óptica. Lo humano como imagen*
}

\author{
Germán Prósperi \\ Universidad Nacional de La Plata, Argentina
}

\begin{abstract}
Resumen
En este artículo nos proponemos retomar la categoría de "máquina antropológica" de Furio Jesi y Giorgio Agamben pero entendiéndola, según una sugerencia de este último, como una "máquina óptica", es decir como un dispositivo constituido por dos ojos y dos miradas: el ojo del alma y el ojo del cuerpo. Nuestro objetivo es explicar los principales aspectos de este dispositivo histórico cuyo funcionamiento consiste en generar imágenes de lo humano.
\end{abstract}

\begin{abstract}
The aim of this paper is to return to the category of "anthropological machine" developed by Furio Jesi and Giorgio Agamben considering it, as suggested by the latter, in terms of an "optical machine", an artifact constituted by two eyes and two looks: the eye of the soul and the eye of the body. Our objective is to explain the main aspects of this historical artifact that produces images of the human.
\end{abstract}

Palabras clave

máquina antropología imagen imaginación dispositivo

\section{Introducción}

En el ensayo "Conoscibilità della festa", Furio Jesi define su categoría de máquina antropológica como un "mecanismo complejo que produce imágenes de hombres, modelos antropológicos" (Jesi, 1977: 15). Giorgio Agamben, por su parte, en L'aperto. L'uomo e l'animale, se refiere a la máquina antropológica de Jesi como una máquina óptica: "la máquina antropogénica [...] es una máquina óptica [...] constituida por una serie de espejos en los cuales el hombre, mirándose, ve su propia imagen ya siempre deformada en rasgos de simio" (Agamben, 2002: 34). Uno de los aportes fundamentales que Agamben realiza al concepto de máquina, tal como aparece en Jesi, es la bipolaridad. Podría decirse que a la máquina mitológica (o antropológica) de Jesi,

* Este artículo es el resultado de la investigación realizada en el marco de la estancia posdoctoral en FFyL-UBA. Por tratarse de un texto relativamente breve, hemos optado por resumir los principales ejes de nuestra investigación. El plan posdoctoral se inscribe en el Proyecto "Comunidades de vida: lo pre-personal, lo animal, lo neutro", dirigido por Mónica B. Cragnolini, Código: PICT 2012/01297. Unidad Ejecutora: Facultad de Filosofía y Letras, UBA.

Keywords

machine anthropology image imagination apparatus 
1. "El horizonte sobre el cual se coloca el modelo maquina mitológica es el espacio donde medimos esta perenne equidistancia de un centro no accesible, respecto al cual no somos indiferentes, sino que somos estimulados a establecer la relación del 'girar en círculo'"' (Jesi, 1980: 105). 2. Sobre la noción de "máquina" en Jesi y Agamben, cfr. Prósperi (2015: 62-83).

3. Según sostiene David Konstan “aparentemente fue Platón quien acuñó la expresión 'el ojo del alma'"' (2013: 134). La misma idea es confirmada por Murray W. Bundy: "Platón insiste entonces en que la verdad es un asunto de recta visión, y es el primero, por lo que sabemos, en hablar del ojo del alma. En este punto de su pensamiento, sin embargo, la imaginación no podría ser identificada con ese ojo" (1922: 367). Platón emplea la expresión

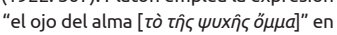
el Libro VII de República (cfr. 533c-d). También aparece en Sofista, esta vez en

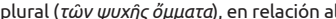
pensamiento dialéctico propio del filósofo.

Martin Heidegger, por su parte, identifica a la filosofía platónica con el inicio de la historia de la metafísica. Haber pensado al ente a partir del concepto de Idea o Forma es lo que convertiría a la filosofía en metafísica: “Desde Platón, el pensar sobre el ser del ente deviene 'filosofía', porque él es un mirar ascendente hacia las "ideas". Pero esta 'filosofía' que comienza con Platón adquiere en lo sucesivo el carácter de lo que más tarde se llama "metafísica", cuya forma fundamental ilustra el mismo Platón en la historia que narra la alegoría de la caverna" (1997: 235). El inicio de la metafísica, como vemos, coincide con el ascenso de la mirada humana hacia las Ideas, es decir con la apertura del ojo del alma, el ojo que permite ver lo invisible. 4. Gilbert Simondon es uno de los filósofos contemporáneos que más ha desarrollado, desde una perspectiva ontológica u ontogenética, la noción de disparidad. El término disparation (disparidad o discordancia) designa una tensión o una incompatibilidad entre dos elementos que forman parte de la misma situación y que sólo una nueva individuación puede resolver. El caso paradigmático de disparation, para Simondon, es por cierto la visión en profundidad, la cual se explica como la resolución de una disparidad entre la imagen percibida por el ojo derecho y la imagen percibida por el ojo izquierdo. Estas dos imágenes bidimensionales dispares requieren de una dimensión tridimensional que resuelva su tensión: "en el mundo tridimensional no hay más dos imágenes, sino el sistema integrado de las dos imágenes" (Simondon, 2013: 208).

5. En Surveiller et punir, Michel Foucault se refiere al panóptico como "el diagrama de un mecanismo de poder llevado a su forma ideal; su funcionamiento, abstraído de todo obstáculo, resistencia

abstraído de todo obstáculo, resistencia
o frotamiento, puede ser representado perfectamente como un puro sistema arquitectónico y óptico: es de hecho una figura de tecnología política que se puede y que se debe separar de todo uso específico" (1975: 207; el subrayado es nuestro). Utilizamos el término "ideal", esta vez en relación al estereoscopio, en el mismo sentido que Foucault. cuya estructura es profundamente circular, ${ }^{1}$ Agamben le introduce dos polos, uno humano o divino y otro natural o animal, convirtiéndola en una máquina bipolar. Su funcionamiento, por eso mismo, se caracteriza por articular y desarticular los dos polos que la constituyen. ${ }^{2}$

En nuestra cultura, el hombre ha sido siempre pensado como la articulación y la conjunción de un cuerpo y de un alma, de un viviente y de un logos, de un elemento natural (o animal) y de un elemento sobrenatural, social o divino (Agamben, 2002: 21).

Ahora bien, en este escrito quisiéramos retomar la categoría de máquina antropológica de Jesi, y al mismo tiempo la estructura bipolar introducida por Agamben, pero enfatizando sobre todo su aspecto óptico, meramente aludido en L'aperto. De tal manera que los dos elementos, el natural o animal y el sobrenatural o divino, en el caso de la máquina óptica, tal como nosotros la entendemos, son el ojo del alma (ojo metafísico) ${ }^{3}$ y el ojo del cuerpo (ojo físico), cada uno con una luminosidad específica, una visión particular y una mirada propia. Al igual que las máquinas de Jesi y de Agamben, la máquina óptica es un dispositivo histórico, por lo cual cada momento o formación de visibilidad produce, a partir de la tensión y, por así decir, de la economía entre los dos ojos y las dos miradas, una cierta imagen del hombre, una imagen en la que esa formación socio-histórica puede reconocerse a sí misma y a su propia humanidad. Por detrás del ojo del alma, funcionando como modelo y paradigma, se encuentra el ojo de Dios; por detrás del ojo del cuerpo, el ojo del animal. La máquina óptica por lo tanto articula e integra dos miradas dispares, ${ }^{4}$ y produce, como un efecto de esa integración, una cierta imagen (o imágenes) de lo humano.

El objetivo del presente artículo es explicar los cuatro rasgos que, a nuestro juicio, constituyen la estructura de la máquina óptica. En primer lugar, se trata de una máquina estereoscópica, cuyos dos ojos, como adelantamos, son el ojo del alma y el ojo del cuerpo. En segundo lugar, la visión binocular de la máquina se caracteriza por una diplopía. En tercer lugar, las dos visiones y las dos miradas se integran y solapan en el quiasma óptico, el centro de la máquina que nosotros identificamos con la imaginación. En cuarto lugar, lo humano es la resolución contingente, es decir histórica, de esa disparidad: la estereopsis o la visión tridimensional.

Consideramos preciso aclarar que no nos proponemos realizar una suerte de arqueología o historia de la máquina óptica sino más bien apoyarnos en algunos autores para explicar su estructura formal. Podría objetarse que la elección de los autores resulta arbitraria. En efecto, bien podríamos haber elegido otros. La objeción, sin embargo, pierde su validez cuando se comprende que lo importante no son los autores abordados sino los aspectos conceptuales que extraemos de sus textos en tanto resultan pertinentes para nuestra categoría. No obstante, en todos los casos se trata de nociones generales que pueden encontrarse en otros autores no abordados aquí.

\section{El estereoscopio como modelo ideal de la máquina óptica ${ }^{5}$}

El estereoscopio es un dispositivo óptico que produce la ilusión de una escena u objeto tri-dimensional a partir de dos imágenes planas diferentes, las cuales son vistas a través del aparato de tal modo que cada ojo ve sólo una de las dos imágenes. Cada imagen está tomada desde dos puntos de vista ligeramente diferentes, separadas aproximadamente por la misma distancia que existe entre los ojos. La imagen derecha representa lo que vería el ojo derecho y la izquierda lo que vería el izquierdo. Cuando se observan las dos imágenes a través de un visor especial, el par de imágenes bi-dimensionales se funden en una única imagen tri-dimensional. Es importante 
destacar que esta imagen tri-dimensional es producida por un aparato específico y que por lo tanto no preexiste a las imágenes bidimensionales. David Brewster, en The Stereoscope. Its History, Theory, and Construction, sostiene enfáticamente que la imagen tridimensional, es decir el efecto o la resolución de la tensión binocular, "es producida a medio camino entre las dos imágenes dispares" (Brewster, 1856: 9). Por eso mismo el funcionamiento de la máquina óptica no consiste más que en producir, como un efecto de relieve o de tridimensionalidad, lo humano. Por eso también, para Jesi y Agamben, la máquina óptica es necesariamente una máquina antropológica. Así como el estereoscopio produce una imagen o escena tridimensional a partir de dos imágenes dispares, así también la máquina óptica produce lo humano a partir de dos miradas o visiones dispares, la del ojo del alma y la del ojo del cuerpo. La máquina óptica es, por eso mismo, estereoscópica. En este sentido, nos resulta imprescindible hacer referencia al célebre artículo de Charles Wheatstone publicado el 1 de enero de 1838 en el Volumen 128 de Philosophical Transactions of the Royal Society of London. Además de proponer el neologismo stereoscope ${ }^{6}$ para designar el dispositivo óptico que había inventado, Wheatstone nos ofrece un diagrama en el que se detallan las diversas partes que lo componen. El gráfico de Wheatstone, reproducido a continuación, es importante para nuestro escrito en la medida en que representa la estructura formal de la máquina óptica.

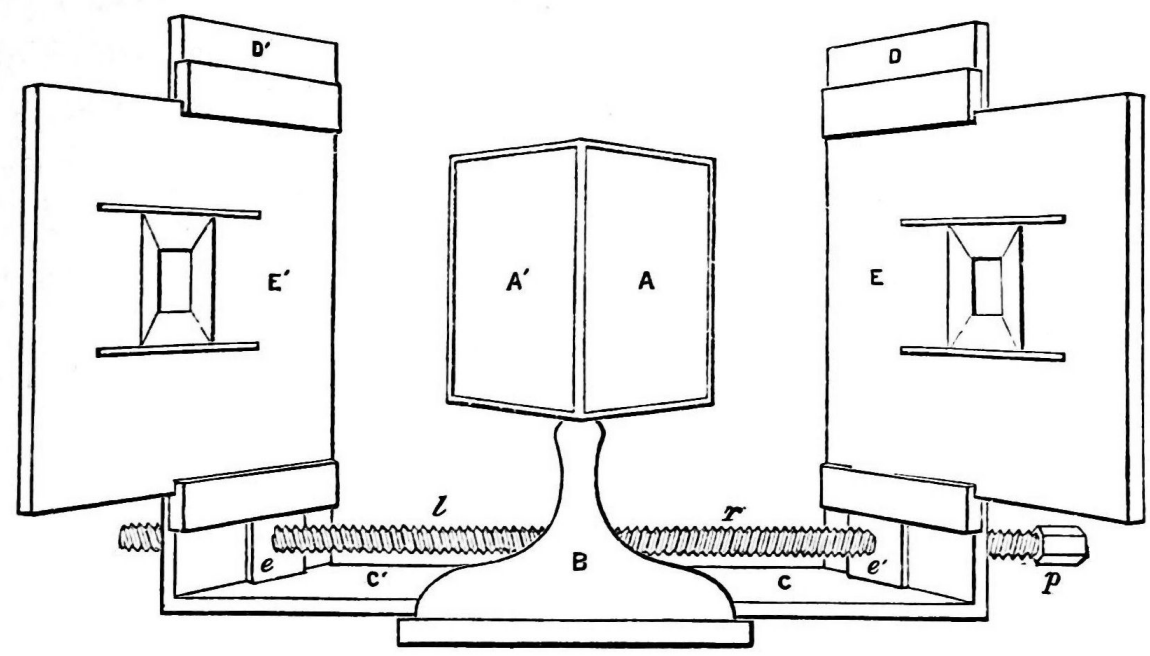

A y A' son dos espejos planos insertados en un soporte de tal manera que cada una de sus partes posteriores forme un ángulo de $90^{\circ}$ con la del otro. $\mathrm{C}$ y C' son dos tableros deslizantes, a los cuales se añaden los tableros verticales $\mathrm{D}$ y $\mathrm{D}$ ' que pueden ser movidos a diferentes distancias de los espejos. Las letras $r$ y $l$ designan un tornillo de madera. Cuando se gira el extremo $p$ del tornillo hacia un lado los dos tableros se aproximan, y al girarlo en la dirección contraria se alejan. E y E' son paneles, a los cuales se fijan las imágenes de tal manera que sus líneas horizontales correspondientes se encuentren en el mismo nivel.

Al igual que hará Brewster algunos años después en su texto sobre el estereoscopio y en varios artículos, Wheatstone parte del principio óptico según el cual "la mente percibe un objeto de tres dimensiones cuando dos imágenes dispares son proyectadas en las dos retinas" (cfr. Wheatstone, 1838: 373). El estereoscopio, como vimos, es un dispositivo que produce, de modo artificial, esta imagen tridimensional. Así explica el inventor inglés el funcionamiento de su reciente descubrimiento:
6. "En tanto deberé referirme con frecuencia a este instrumento, será conveniente darle un nombre específico, propongo por lo tanto que sea llamado Estereoscopio, para indicar su propiedad de representar figuras sólidas" (Wheatstone, 1838: 374). 
7. La misteriosa instancia en la que se articulan e integran ambas imágenes y ambas miradas, que en su artículo Wheatstone identifica simplemente con el término mind (mente o espíritu), a lo largo de la historia de la metafísica, como veremos en el apartado 3 , ha sido la imaginación.

8. Sobre la noción de diplopía, cfr. Pons Moreno et Martínez Verdú (2004: 210-220).
El observador debe ubicar sus ojos tan cerca como sea posible de los espejos, el ojo derecho delante del espejo derecho, el ojo izquierdo delante del espejo izquierdo, y debe mover los paneles deslizantes E y E' hasta que las dos imágenes reflejadas coincidan en la intersección de los ejes ópticos, y formen una imagen de la misma magnitud aproximadamente que cada una de las imágenes reflejadas. Las imágenes coincidirán cuando los paneles se encuentren en diversas posiciones, y consecuentemente cuando sean vistas bajo diferentes inclinaciones de los ejes ópticos; pero hay una sola posición en la cual la imagen binocular será vista inmediatamente simple [single], con su propia magnitud, y sin fatiga en los ojos, porque solo en esta posición las relaciones ordinarias entre la magnitud de las imágenes sobre la retina, la inclinación de los ejes ópticos, y la adaptación del ojo a la visión distinta en distancias diferentes son preservadas (Wheatstone, 1838: 375).

Esta explicación de Wheatstone nos permite comprender el funcionamiento específico de nuestra categoría. Las imágenes ubicadas en los paneles deslizantes E y E' designan los objetos propios de cada ojo: el ojo del alma y el ojo del cuerpo. El espacio que se extiende entre el espejo A (en caso de que ubiquemos allí el ojo del cuerpo) y el panel E designa el campo de visibilidad propio de la mirada corpórea; el espacio que se extiende entre el espejo A' y el panel E', al contrario, el campo de visibilidad propio de la mirada anímica o espiritual. El resultado de estas dos imágenes y de estas dos miradas correspondientes a los dos paneles, uno visto por el ojo derecho y otro por el izquierdo, sostiene Wheatstone, genera una imagen tridimensional en relieve. El producto o el efecto de estas dos imágenes dispares, en nuestro caso identificadas con la imagen vista por el ojo del cuerpo y con la imagen vista por el ojo del alma, una vez que son integradas en la mente, es lo que la historia de la metafísica occidental ha llamado homo sapiens. ${ }^{7}$

\section{Diplopía}

La visión doble de un objeto se conoce como diplopía. ${ }^{8}$ Existen dos formas de diplopía: la diplopía homónima, en el caso en que el objeto se encuentre más allá del punto de fijación; la diplopía cruzada, en el caso en que el objeto se encuentre más acá del punto de fijación. La diplopía se produce cuando los ojos no pueden converger en un mismo punto de fijación. Cada ojo posee un punto retiniano específico que luego se superpone en el nervio común formando una imagen única. Estos puntos, sin embargo, son necesariamente dispares. El mecanismo del estereoscopio, por eso mismo, consiste precisamente en fusionar las imágenes binoculares. Lo mismo sucede en el caso de la máquina óptica. Cada ojo, el del alma y el del cuerpo, posee un punto retiniano propio y diverso al del otro ojo. En consecuencia, cada ojo tiene también su propio objeto y su campo de visibilidad particular. Al ser ambas imágenes dispares, la imagen generada a partir de su integración no existe de forma pura. Cuando se impone el objeto de una de ellas, el otro subsiste de forma desdoblada y especular. La diplopía de la máquina óptica muestra la naturaleza fantasmática de las miradas. La resolución de la disparidad binocular deja subsistir siempre los objetos de las dos miradas bajo una forma especular y espectral. Cuando el funcionamiento estereoscópico resuelve las dos imágenes dispares en una única imagen tridimensional, la cual se produce a medio camino de las dos imágenes previas, éstas no desaparecen, sino que sobreviven o subsisten, más bien, como fantasmas o restos espectrales. Por eso cada mirada, cada ojo, está desviado respecto del otro. Esta desviación se conoce como estrabismo y es una de las causas principales de diplopía. La máquina óptica intenta corregir esta desviación produciendo una imagen en relieve o en profundidad. Esta producción, histórica y maquínica, es decir contingente, concierne fundamentalmente a lo humano, a la humanidad del homo sapiens. La 
producción de lo humano, en consecuencia, requiere una rectificación de la desviación, una convergencia eventual de dos miradas cuyos ojos, por fuerza, se han extraviado. La historia de la metafísica de Occidente, según nuestra perspectiva, no es sino la aventura de este extravío.

\subsection{Espacio de Panum: la franja antropológica}

El horóptero, término acuñado por Francisco de Aguilón, 9 se define como el lugar geométrico de los puntos del espacio cuyas imágenes caen en puntos retinianos correspondientes. ${ }^{10}$ Como se sabe, los dos puntos retinianos relativos a las dos fóveas ${ }^{11} \mathrm{y}$ demás pares asociados a un punto cualquiera visto no doble, se denominan puntos correspondientes. ${ }^{12}$ La visión única o simple producida por la integración de las dos imágenes monoculares se denomina haplopía; la visión doble, como hemos indicado, diplopia. ${ }^{13}$ Ahora bien, según estos principios, cualquier punto que caiga fuera del horóptero, es decir de la superficie en la que convergen los ejes visuales debería verse doble. Sin embargo, es posible corroborar que alrededor de la curva del horóptero existe un intervalo espacial, una suerte de margen más o menos extenso en el que se produce una visión haplópica y no diplópica. Para explicar este fenómeno, Peter Ludvig Panum conjeturó que la correspondencia retiniana no es punto a punto, sino punto a área (cfr. Panum, 1858). De tal manera que no es estrictamente necesario que la imagen de un punto de fijación $\mathrm{x}$ recaiga sobre el punto correspondiente de la otra retina, sino sólo que esté dentro del área correspondiente. Estas áreas retinianas se denominan áreas de Panum y se corresponden con el espacio alrededor del horóptero donde se produce una visión haplópica, llamado espacio de Panum. ${ }^{14}$

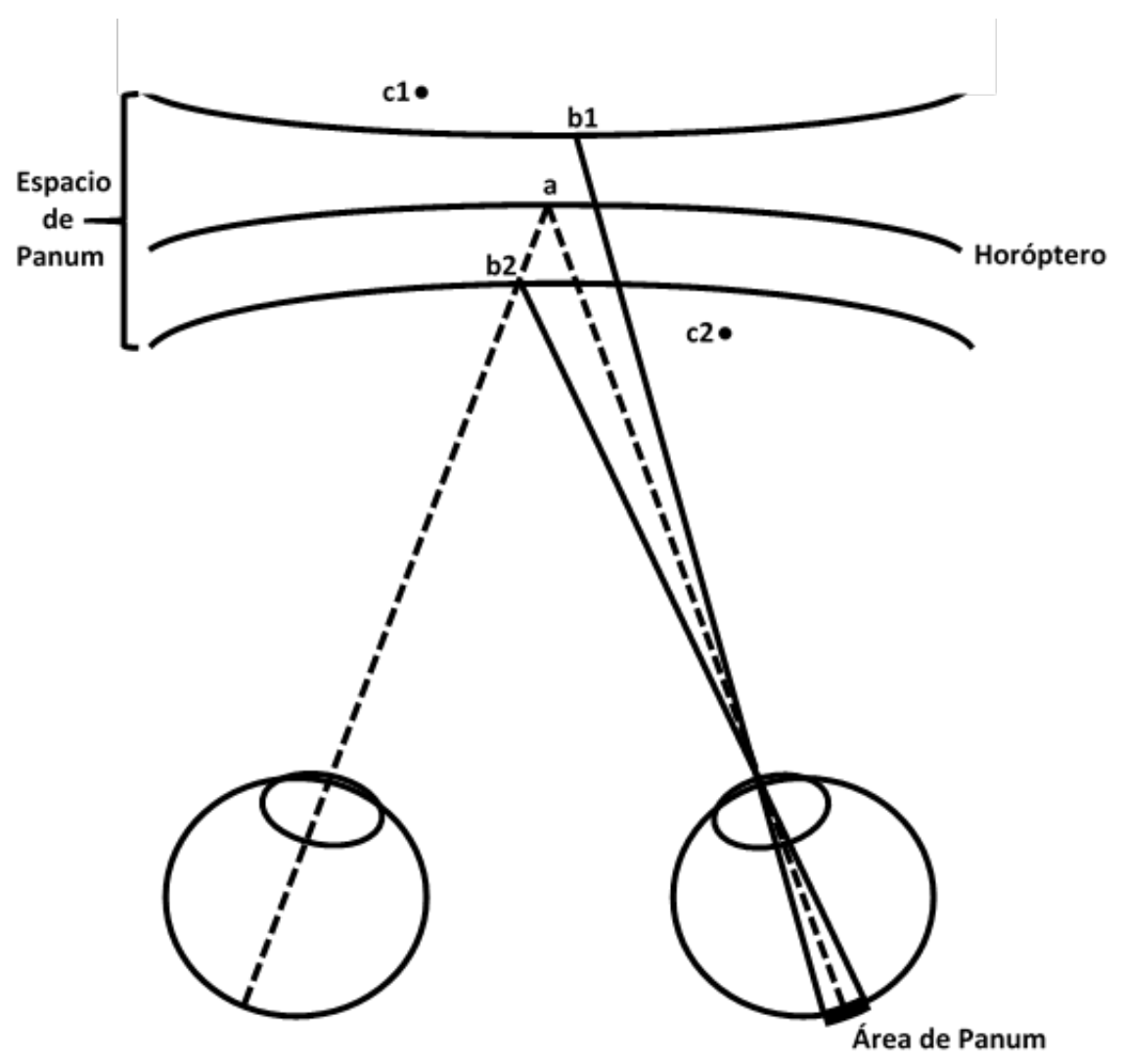

Según este diagrama, a designa el punto de fijación, es decir el punto sobre el horóptero en el que convergen los ejes visuales de ambos ojos; $b_{1}$ y $b_{2}$ constituyen los puntos extremos que delimitan el espacio de Panum y que se corresponde con el área
9. Sobre la vida de Francisco de Aguilón, cfr. Ziggelaar (2011: 168-174). Sobre algunos aspectos generales de su teoría óptica, cfr. Ziggelaar (2012: 84-104).

10. Sobre la noción de "horóptero", cfr. Pons Moreno et Martínez Verdú (2004: 231-263); Howard et Rogers (1995: 14-18, 31-68).

11. La fóvea es el área de la retina donde se enfocan los rayos luminosos. Tiene un radio de unos $0^{\prime} 4 \mathrm{~mm}$ y está compuesta por una densa concentración de conos. La fóvea constituye el centro de la visión nítida y subtiende un arco de aproximadamente $1^{\circ}$, en comparación con los $240^{\circ}$ del ángulo visual que subtiende toda la retina. Cuanto más lejos está un estímulo de la fóvea, menor es nuestra capacidad de discriminación.

12. Sobre la noción de "puntos correspondientes", cfr. Pons Moreno et Martínez Verdú (2004: 193-203).

13. "De acuerdo a la óptica fisiológica moderna, la fusión de las dos imágenes en la visión binocular se produce cuando los puntos de fijación del objeto son 'pintados' en los puntos correspondientes de ambas retinas. El fenómeno de diplopía surge en los casos en que los puntos de fijación del objeto caen en puntos dispares sobre las superficies de cada retina" (Raynaud, 2016: 79).

14. Sobre el área y el espacio de Panum, cfr. Wade et Ngo (2013: 92-94); Pons Moreno et Martínez Verdú (2004: 273-280); Raynaud (2016: 89-93). 
5. En la medida en que el área de Panum se define como el espacio en el que pueden fusionarse las imágenes dispares y producir una visión haplópica se la denomina también área fusional de Panum. Sobre el área fusional de Panum, $c f r$. Howard et Rogers (1995: 13, 42, 53, 159, 315).

16. Nos referimos por supuesto a la célebre metáfora que emplea Descartes en la sexta meditación metafísica: "La naturaleza también me enseña, por medio de esas sensaciones de dolor, hambre, sed, etc., que yo no sólo estoy en mi cuerpo como un piloto en su navío, sino que estoy unido estrechísimamente y como mezclado con él, de tal manera que formo una sola cosa con él" (AT, VII: 81). de Panum localizada en las retinas. Las áreas de Panum suponen la existencia de una tolerancia en los mecanismos fusionales que favorece la fusión aun cuando no exista una coincidencia total de las imágenes retinianas. ${ }^{15}$

Ahora bien, los puntos que caen fuera del espacio de Panum se ven dobles, es decir en diplopía. La franja adyacente al horóptero, representa el espacio en el que los puntos, aunque levemente dispares, son vistos de forma haplópica, es decir como una imagen única. Los puntos que se ubiquen por fuera de este espacio son vistos de forma diplópica. Si un punto se encuentra más allá del punto de fijación (en nuestro esquema: c1) se trata de una diplopía homónima o no cruzada; si se encuentra más acá (c2 en nuestro esquema) se trata de una diplopía heterónoma o cruzada.

Estas nociones ópticas se revelan altamente significativas para nuestra categoría metodológica. La máquina óptica, hemos dicho, funciona articulando o fusionando las imágenes provenientes de cada ojo, el del cuerpo y el del alma, y produciendo una imagen tridimensional única. La fusión de las imágenes no supone una anulación de sus elementos particulares, sino más bien una integración de las diferencias específicas de cada imagen. El espacio de Panum de nuestro esquema representa el espacio de lo humano, la franja antropológica, es decir la región, generada por la máquina, en la que lo humano puede ser pensado como una instancia única o como un compuesto en el que los dos elementos, el corporal y el espiritual, se mantienen en una relación aún más íntima que la que existe entre un piloto y su navio. ${ }^{16} \mathrm{La}$ historia de la metafísica occidental ha tendido a producir lo humano en este espacio haplópico. Pero por eso mismo, no ha dejado de verse acosada por la diplopía. Incluso en el espacio de Panum existe la disparidad, sólo que la máquina óptica funciona rectificándola y produciendo una imagen única. El punto de fijación, en este sentido, es un punto mítico, u-tópico. Más allá de la franja antropológica, en la zona del punto $c 1$, los hombres han proyectado las existencias angélicas; más acá, en el punto $c 2$, las existencias animales. El ángel es la sombra fantasmal o espectral del más allá de lo humano; el animal, la sombra fantasmal o espectral del más acá de lo humano. Dicho de otro modo: el ángel es la diplopía homónima o no cruzada del hombre; el animal, la diplopía heterónoma o cruzada. Lo interesante es que entre el más allá angélico y el más acá animal estrictamente hablando no hay nada, sólo un punto ciego, una imagen tridimensional vacía. Como se sabe, existe una zona en la retina, en el polo posterior del ojo, en la que no hay células sensibles a la luz debido a que es el lugar en el que se inserta el nervio óptico. Se denomina a esa región de la retina, en la que no hay sensibilidad óptica, punto ciego. En nuestra perspectiva, este punto ciego es precisamente lo humano, lo que la máquina produce y al mismo tiempo captura para funcionar. Normalmente no percibimos su existencia debido a que el punto ciego de un ojo es suplido por la información visual que nos proporciona el otro. Ante la falta de información visual en la zona del punto ciego, la máquina óptica recrea virtualmente y rellena esa pequeña área en relación al entorno visual que la rodea. Consideremos el siguiente experimento:

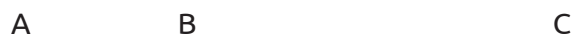

Sitúe su ojo izquierdo aproximadamente a $20 \mathrm{~cm}$ de las letras, tápese el ojo derecho y, fijando la vista con el ojo izquierdo en la letra $C$ que está a la derecha, aleje lentamente el papel o la pantalla y podrá observar cómo desaparece la letra B al entrar en el área sin sensibilidad óptica; al continuar alejando el papel o la pantalla, la letra B volverá a aparecer.

Sea A el animal, B el hombre y C el ángel. La tradición metafísica ha intentado colmar el punto ciego de lo humano, el punto donde el hombre desaparece, con las más variadas imágenes: zoon lógon echon, animale rationale, cretura Dei, ego cogito, 
Geist, etc. Lo cierto es que el lugar específico de lo humano es el punto ciego. Esto no significa ningún privilegio, por supuesto; simplemente significa que el hombre no posee una esencia que lo defina ni una naturaleza substancial. Como dirá Georges Bataille del sistema hegeliano: horror a la mancha ciega. ${ }^{17}$ La metafísica antropocéntrica teme al punto de desaparición, teme a la posición en la que, de repente, el hombre dejaría de verse. El horror a la mancha ciega es el horror frente a la condición fantasmática o espectral de lo humano. El fantasma que acosa al hombre no tiene rasgos angélicos ni animales; el verdadero fantasma es el hombre mismo. El vacío espectral no se encuentra ni más allá ni más acá, ni en la pureza del espíritu ni en la brutalidad de la carne; se encuentra en el centro mismo de lo humano. El punto de fijación, por eso mismo, no puede evitar la diplopía. No es que al contemplar al hombre se insinúe la presencia sigilosa, espectral, del ángel o del animal; es que al contemplar al hombre no contemplamos nada. Pasamos del ángel al animal y del animal al ángel sin encontrarnos con ninguna substancia intermedia, como si el hombre fuese poco más que un espesor vacío, un cero de ser que no es una nada, un mínimo de ser. El punto de fijación, en consecuencia, el punto en el que la máquina óptica nos obliga a contemplar el centro esencial de lo humano, es en verdad un punto ciego. Sólo hay diplopía, disparidad. La visión haplópica es un mito generado por la máquina óptica. Dice Foucault: el hombre, a partir de Nietzsche, de Hölderlin, de Mallarmé, ha muerto. Decimos nosotros: el hombre ha nacido muerto. A diferencia de la tesis foucaultiana, su fecha de nacimiento no es reciente, sino simultánea a la historia de la metafísica y a la máquina óptica. Pero no se trata de proferir frases provocadoras. Expliquémonos: afirmar que el hombre ha nacido muerto significa afirmar que siempre ha sido el efecto tridimensional generado por un dispositivo óptico. El hombre ha sido una imagen, eso es todo. Y ha sido una imagen porque sólo así ha podido ser rellenado el punto ciego, el vacío que se abre, aún más amenazante que los ángeles y los animales, en el centro mismo de lo humano. Nietzsche ha afirmado que el hombre es una cuerda tendida entre la bestia y el superhombre. ¿Qué es esa cuerda? Es una imagen, un fantasma, un punto ciego, un cero de ser que no es una nada, un espesor que no es un vacío absoluto. Preguntarse por lo humano significará preguntarse, entonces, por el estatuto paradójico de esta singularidad en el límite de la ontología. Del animal al ángel, de la bestia al superhombre: el hombre no existe, es sólo la imagen de un puente ontológico que, en cuanto tal, no pertenece a lo existente tal como lo entiende la metafísica.

\section{El quiasma óptico y la imaginación}

Como se sabe, los nervios ópticos conectan los ojos con el cerebro. Cada nervio mide unos $304 \mathrm{~mm}$ y contiene alrededor de 250.000 axones. Luego de pasar por la retina en el disco óptico, el nervio óptico se extiende unos $5 \mathrm{~cm}$ hasta el quiasma óptico. En los primates y otros mamíferos, los axones que provienen de las retinas se cruzan en el quiasma y prosiguen hacia el otro lado del cerebro. Este cruzamiento de los axones se denomina decusación. Esta palabra proviene del latín decussatio que significa intersección de dos líneas en forma de cruz. El término quiasma, por su parte, proviene

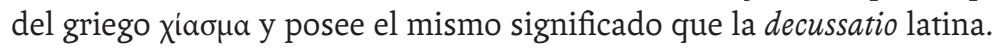

Galeno sostiene que el quiasma óptico deriva su nombre de la letra $\mathrm{X}($ chi $) \cdot{ }^{18} \mathrm{En}$ el centro de la $\mathrm{X}$, aunque sin cruzarse ni superponerse, el espíritu visible proveniente de ambos ojos se unifica en una única imagen y una única experiencia que le llega, recién entonces, al cerebro. La finalidad del quiasma, por ende, consiste en la resolución de la diplopía o de la visión doble. El quiasma representa el punto de correspondencia de ambas imágenes, cuyos objetos, sin embargo, "son diferentes para el ojo derecho y para el ojo izquierdo" (Galeno, 1978: 823). ${ }^{19}$
17. En L'expérience intérieure, Bataille consigna: "En el 'sistema', poesía, risa, éxtasis no son nada, Hegel se desembaraza rápidamente de ellos: él no conoce otro fin más que el saber. Su inmensa fatiga se liga a mis ojos al horror de la mancha ciega [l'horreur de la tache aveugle]" (1973, V: 130).

18. En De usu partium corporis humani, Galeno sostiene que el término "quiasma" deriva su nombre de la letra X (chi). Cfr. Galeno (1978: 820). 19. Muchos siglos después, Ibn alHaytham, conocido en Occidente como Alhacén, en el famoso Kitab al-Manazir retoma las ideas de Galeno y sostiene que las imágenes provenientes de cada nervio óptico convergen en el quiasma óptico, formando una imagen única. Recién entonces, aclara el físico árabe, la visión se produce. De la parte posterior de los ojos parten los nervios ópticos. Luego de encontrarse, en el eje de la X, se separan y se dirigen hacia el cerebro. Sobre Alhacén y la visión binocular, cfr. Raynaud (2003:79-99). 
21. Podríamos citar innumerables ejemplos que apoyan este lugar intermedio, quiasmático, de la imaginación en relación a lo sensible y lo inteligible. Giorgio Agamben, por ejemplo, refiere: “La imaginación recibe así un rango decisivo en todos los sentidos: en el vértice del alma individual, en el límite entre lo corpóreo y lo incorpóreo, lo individual y lo común, la sensación y el pensamiento, representa el residuo último que la combustión de la existencia individual abandona en el umbral de lo separado y de lo eterno. En este sentido, la imaginación -y no el intelecto - es el principio definitorio de la especie humana" (2007: 51-52); y también, un poco más tarde: "es en la imaginación donde tiene lugar la fractura entre lo individual y lo impersonal, lo múltiple y lo único, lo sensible y lo inteligible $y$, a la vez, la tarea de su dialéctica recomposición" (2007: 56).

20. Recordemos que para Aristóteles la

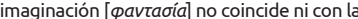
sensación, ni con la opinión, ni con la ciencia ni con la inteligencia (cfr. De anima, 428a). Sobre la fantasía en Aristóteles, cfr. Schofield (1995: 250-279). Más recientemente Emanuele Coccia, tanto en La transparenza delle immagini (2005) cuanto en La vita sensibile (2010), ha reflexionado ampliamente sobre la noción de "imagen" y de "imaginación", sobre todo - aunque no sólo - en la cultura medieval de tradición aristotélica.

En La vita sensibile, por ejemplo, Coccia sostiene que el ser de las imágenes no se confunde ni con el ser de los objetos ni

con el ser de los sujetos. En este sentido, designa un afuera que ha subsistido, como los sueños, en los márgenes de la tradición occidental (continúa en página 193)

22. Esta expresión, "oculus imaginationis", figura en un dibujo de la página inicial del Ars Memoriae (Tratado Primero, Sección II, Parte III, 1619, Tomo II: 47), recopilado en el opus magnum de Fludd: Utriusque Cosmi maioris salicet et minoris metaphysica physica, atque technica Historia. Por otra parte, en el Libro X de la Sección I del Tratado Primero de la obra magna, titulado "De triplici animae in corpore visione", Fludd habla de la triple visión del hombre y del lugar intermedio que ocupa la imaginación o fantasía. El ojo o la visión de la imaginación (in imaginatione seu phantasia) hace posible la articulación y la conexión del ojo o la visión de los sentidos (per sensum) con el ojo o la visión intelectual (intellectualis) (cfr. Fludd 1619: 204-221). La expresión "ojo de la imaginación" también la encontramos en William Blake: "Lo que Jesús vino a remover fue la Filosofía Pagana o Platónica

que enceguece el Ojo de la Imaginación [Eye of Imagination] El Hombre Real" (1988: 664). En efecto, Blake y los románticos en general encuentran en Cristo, es decir en

el Verbo encarnado, la instancia que les permite resolver el hiato entre lo Uno y lo Múltiple, entre Dios y el Mundo, entre el Sujeto y el Objeto (cfr. Engell 1981: 251-254).
A principios del siglo XVII, el célebre físico y matemático jesuita Francisco de Aguilón, en su Opticorum Libri Sex philosophis juxta ac mathematicis utiles, le adjudica la función del quiasma óptico al sentido común y a la facultad imaginativa. La propositio XVIII del segundo Libro, en la cual se discuten cuestiones relativas a la visión binocular, resulta, en este sentido, esencial. La disparidad de las imágenes percibidas por cada ojo, razona De Aguilón, debería provocar una visión confusa del objeto: "dado que las imágenes en cada ojo son dispares [minime sibi congruant], la imagen de la cosa debería aparecer confusa y perturbada [confusa ac perturbata] al sentido primario" (De Aguilón, 1633: 141). El término congru re es decisivo. Las imágenes de cada ojo no poseen congruencia o, más bien, poseen un mínimo de congruencia. Esto significa que son dispares. Tratándose de dos imágenes incongruentes, infiere el matemático jesuita, no debería producirse una imagen nítida. Sin embargo, es precisamente esto último lo que sucede. De Aguilón lo juzga milagroso, y la explicación que ofrece es la siguiente:

\begin{abstract}
La razón de que los cuerpos se vean como objetos únicos no está en que imágenes aparentes formadas en cada ojo de forma separada entren en coalescencia [mutuo exacte congruunt], sino en que el sentido común [communis sensus] imparte su ayuda a ambos ojos por igual, ejerciendo su propio poder de la misma manera que los ojos ejercen el suyo cuando convergen su mirada por medio de sus ejes ópticos. De cualquier cuerpo, por ende, que cada ojo ve de manera conjunta, el sentido común produce una única noción, no ya compuesta por las dos imágenes que pertenecen a cada ojo, sino perteneciendo a y siendo acomodado por la imaginación [imaginatuae facultati] a la cual (el sentido común) se la asigna (De Aguilón, 1633: 141).
\end{abstract}

Este pasaje de De Aguilón es importante porque encontramos una clara relación entre la función específica del quiasma óptico, lugar en el que - según Galeno y Alhacén - las imágenes dispares se fusionan, y la función del sentido común y la imaginación. Retomando un tópico común de la filosofía medieval y renacentista, sobre todo en su vertiente aristotélica, De Aguilón ubica a la facultad imaginativa en el lugar intermedio entre la sensibilidad y la inteligencia. ${ }^{20}$ Este punto es fundamental para nuestra categoría de máquina óptica. Como hemos indicado, la máquina funciona articulando los dos polos que la constituyen, el ojo del alma y el ojo del cuerpo. Al igual que en la fisiología del sistema óptico, esta articulación, tal como se creía desde la Antigüedad hasta la Edad Moderna, sucede en el quiasma, cuya función De Aguilón identifica con la imaginación. Lo cual significa que el hiato o el topos en el que convergen (y al mismo tiempo divergen) la mirada del ojo del alma y la del ojo del cuerpo es precisamente la imaginación. ${ }^{21}$ La consecuencia inmediata que podemos extraer de esta constatación es la siguiente: si lo humano, las diversas imágenes de lo humano que la máquina óptica ha ido produciendo a lo largo de la historia, es el efecto o el resultado de la articulación de la mirada del ojo del alma y de la mirada del ojo del cuerpo; si estas miradas, por otro lado, se fusionan en el quiasma y si esa fusión, a su vez, como muestra De Aguilón, es propia de la potencia imaginativa, entonces lo humano, la humanitas, no es otra cosa que el producto de la imaginación, un fantasma generado (y al mismo tiempo contemplado), para retomar una expresión de Robert Fludd, por el oculus imaginationis. ${ }^{22}$

\section{Estereopsis}

Ian Howard y Brian Rogers, en Binocular Vision and Stereopsis, sostienen que la visión binocular está íntimamente vinculada a la sensación de profundidad. "La expresión 'visión binocular' se reserva usualmente para aquellos animales que poseen un 


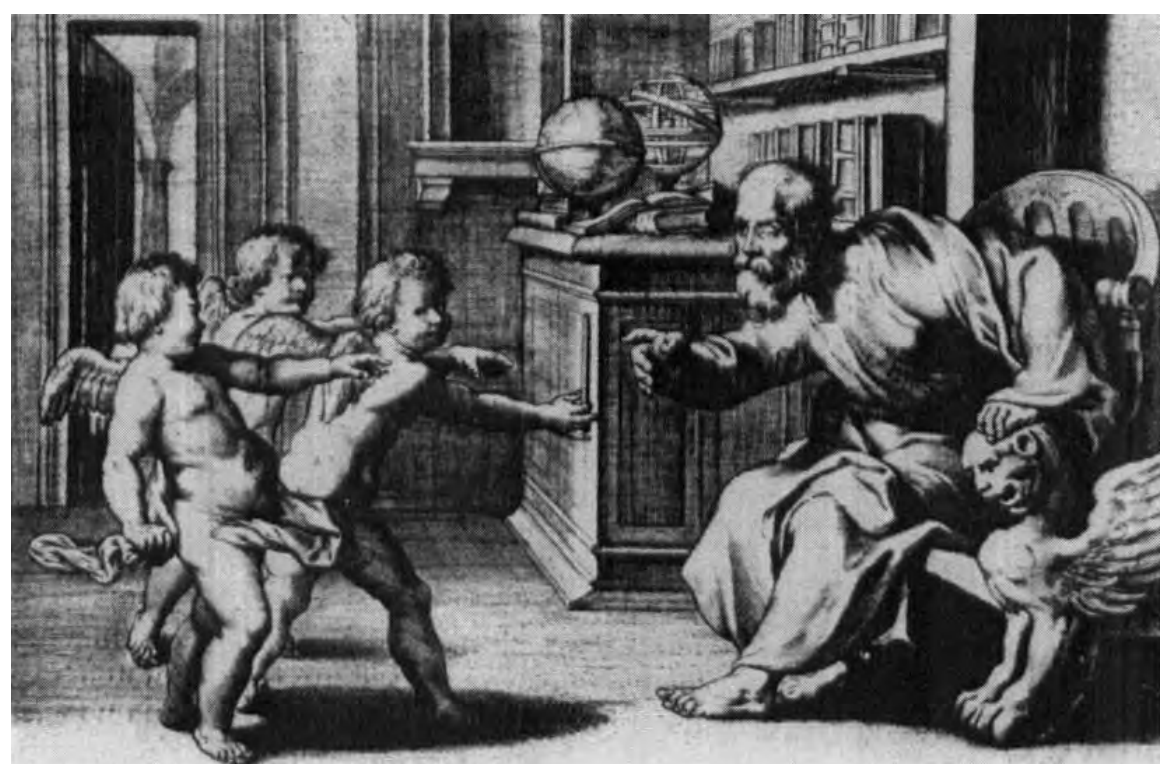

amplio espacio de superposición binocular [overlap] y que la usan para codificar la profundidad [depth]" (Howard et Rogers, 1995: 2). Nos interesa destacar dos términos: superposición o solapamiento y profundidad, overlap y depth. ${ }^{23} \mathrm{El} \mathrm{fun-}$ cionamiento de la máquina óptica se caracteriza por solapar las dos miradas que la constituyen, la del ojo del alma y la del ojo del cuerpo, y por producir, a partir de ese solapamiento, un efecto de la profundidad. Hemos dicho que ese efecto, que esa ilusión de profundidad, es precisamente lo humano. Cada formación histórica tiene su modo de solapar las miradas y, en consecuencia, su modo de generar una cierta profundidad. Lo cual significa que lo humano es el efecto perceptivo generado por la estereopsis de la máquina óptica. Como indican nuevamente Howard y Rogers: "La expresión 'estereopsis binocular' se emplea habitualmente para designar la impresión de profundidad provocada por las imágenes binoculares" (Howard et Rogers, 1995: 2). Por tal motivo, hemos definido a la máquina óptica como un estereoscopio, es decir como un dispositivo que genera, a partir del solapamiento de las imágenes dispares, la visión tridimensional o en profundidad. El Dr. David Brewster, a quien ya nos hemos referido con anterioridad, explica el principio de la estereopsis:

La creación estereoscópica se debe meramente a la superposición de las dos imágenes planas por el dispositivo óptico [optical apparatus] empleado, y a la percepción distinta e instantánea de la distancia por la convergencia de los ejes ópticos sobre los puntos similares de las dos imágenes que el estereoscopio ha unido (Brewster, 1856: 3).

Tenemos aquí todos los elementos para explicar la formación de las diversas imágenes históricas que la máquina óptica produce del hombre. En líneas generales, el funcionamiento de la máquina se estructura en dos momentos: 1) la máquina superpone, es decir articula, integra, las imágenes que le llegan de los dos ojos que la constituyen: el ojo del alma y el ojo del cuerpo; 2) provoca una percepción de profundidad, de distancia, de tridimensionalidad, a partir de esa superposición. En consecuencia, la máquina óptica o, para emplear la expresión de Brewster, el optical apparatus no es sino, como hemos dicho, un estereoscopio.

\subsection{Entre las bestias y los dioses}

El tercer capítulo del "Liber Primo" del Opticarum Libri Sex de Francisco de Aguilón, autor al que ya hemos hecho referencia, trata de la percepción de los objetos comunes.
Grabado de Peter Paul Rubens que ilustra el Libro I del Opticorum Libri Sex de Francisco de Aguilón, Antverplae, Ex Officina Plantiniana, 1633.

23. No es causal que ambos conceptos (en su versión francesa: empiétement y profondeur) sean centrales en el pensamiento de Merleau-Ponty y que adquieran toda su relevancia a la hora de plantear una ontología (del quiasmo o de la carne) diversa a la cartesiana. 
El capítulo se abre con una ilustración de Peter Paul Rubens que nos interesa particularmente. En ella se representa un experimento óptico que demuestra lo difícil que resulta percibir la profundidad cuando se utiliza un solo ojo.

El científico intenta determinar la distancia precisa en la que se encuentra una vara sostenida por un putto. Como explican Howard y Rogers, De Aguilón "era consciente de que la visión binocular mejora el sentido de la profundidad" (1995: 15). Uno de los niños alados, además, repite el mismo experimento que el científico e intenta calcular, también con un ojo cerrado, la distancia a la que se encuentra la vara. La mano izquierda del estudioso descansa sobre una gárgola cuyo cuerpo posee rasgos decididamente animales. De algún modo, la mirada del científico, del hombre, tiene lugar en este espacio intersticial entre el ángel y el animal. La gárgola, cuyos ojos parecieran inclinarse hacia abajo por la presión soberana de la mano humana, y los putti, que contemplan la vara desde una perspectiva inversa a la del sabio, constituyen los dos extremos de una región en cuyo centro, sin duda infundado, se encuentra lo humano. La gárgola animal y los niños alados son las figuras a través de las cuales Rubens nos ha representado el ojo del cuerpo y el ojo del alma. Entre la mirada sometida de la gárgola y las miradas intrigantes de los putti o, para utilizar una expresión de JeanPierre Vernant, "entre las bestias y los dioses" (cfr. Vernant, 2007, I: 723-750) se abre una zona, un leve espesor, que no es más que lo humano en cuanto tal, lo humano como imagen tridimensional. La profundidad que percibe el científico no es sino la profundidad de lo humano, la imagen tridimensional generada por la máquina óptica. No hay que confundir la profundidad de la imagen humana o de lo humano como imagen con la profundidad de una esencia o de un fundamento; es más bien al contrario: la imagen se opone a la esencia. La profundidad de la imagen, la tridimensionalidad de la imago antropológica, no es equivalente a la profundidad de la esencia. Mientras que ésta encuentra su profundidad remontándose hasta un fundamento, aquella la encuentra en el funcionamiento estereoscópico de un dispositivo histórico-político. En este último caso, la profundidad es efecto; en el caso de la esencia, es causa, es decir fundamento. Por eso cuando afirmamos que lo humano es producido como un efecto de profundidad, como un relieve o un volumen tridimensional, no queremos decir que el hombre sea un ser más profundo, en un sentido existencial o metafísico, que los demás seres. El hombre es profundo porque es una imagen, es decir porque es una entidad que, a diferencia del cuerpo que posee una materialidad palpable y a diferencia del alma que posee una inmaterialidad impalpable, no es ni estrictamente material ni inmaterial, ni papable ni impalpable. Por tal motivo, no puede fundarse ni en su cuerpo ni en su alma, ni en la masa opaca de su carne ni en la inteligibilidad etérea de su espíritu. En suma, no es que el hombre sea una imagen porque es un ser profundo, sino que es un ser profundo porque es una imagen.

El grabado de Rubens nos demuestra entonces que la profundidad humana no consiste en una esencia, sino en un efecto imaginario, un mecanismo óptico. Entre la gárgola y los putti, entre el animal y el ángel, como bien sabía Rainer Maria Rilke, se abre un espesor que en rigor de verdad está perfectamente vacío. La profundidad, por eso mismo, es una profundidad vacía, la profundidad de un vacío. Dicho de otro modo: entre la gárgola y los niños alados no se encuentra la esencia humana, aquello que revelaría finalmente la especificidad del hombre; se encuentra un vacío, la "especificidad" de un vacío. Lo cual significa que si existe algún tipo de especificidad o excepcionalidad humana esta no es más que la imposibilidad de poseer algo especí-

24. En su estructura formal, esta aseveración se acerca al argumento esbozado por Quentin Meillassoux cuando afirma, por ejemplo, que "es posible demostrar la absoluta necesidad de la no-necesidad de toda cosa" (2006: 84; el subrayado es de Meillassoux). Es absolutamente necesario que no exista nada necesario; de la misma manera, la única especificidad del hombre es su carencia de especificidad. fico o excepcional. Lo propio del hombre es que no posee nada propio. ${ }^{24}$ Llamamos imagen antropológica al modo en que una determinada formación histórico-social se re-presenta a sí misma lo que significa ser humano, lo que significa la humanitas del homo sapiens. Este desierto que han dejado vacío los dioses al partir y los animales al nunca llegar, esta suerte de pausa entre la animalidad y la divinidad, este no ser ya animal pero no ser aún dios, ha sido colmado con diversas imágenes de lo 
humano. Por eso la humanitas es siempre el efecto tridimensional, estereoscópico, generado por la articulación del ojo corpóreo del animal (el ojo aún-no humano) con el ojo espiritual del dios (el ojo ya-no humano). Así como la estereopsis se produce cuando la imagen del ojo derecho se integra con la imagen del ojo izquierdo, asimismo la imagen antropológica se produce cuando la imagen del ojo corporal, el ojo de esa "máquina compuesta de miembros, tal como se encuentra en un cadáver" (Descartes, AT, VII: 26), se integra y solapa con la imagen del ojo anímico, el ojo de esos espíritus puros que para Descartes eran los ángeles. Los hombres, dice Rilke en un sentido opuesto al de Heidegger, no ven lo abierto. ${ }^{25}$ A diferencia de los animales, que ven lo abierto porque viven en un eterno presente y no son conscientes de la muerte y a diferencia también de los ángeles que son espíritus inmortales, los hombres, apenas al nacer, tienen los ojos dados vuelta. Pero ¿qué ven, qué vemos, con esta mirada invertida o, quizás, introspectiva? No vemos nada, un vacío. Precisemos: vemos una imagen; una imagen profunda, incluso. Vemos una cierta profundidad, es verdad, pero una profundidad tan vana e infundada como el contenido que pareciera animarla. Vemos, en suma, el espesor de un vacío que, sin embargo, no es una simple nada. Este espesor, lo hemos visto, es producido por la imaginación, por el quiasma óptico que integra las imágenes provenientes del ojo del cuerpo y del ojo del alma. En un interesante texto sobre Ibn al-'Arabī, Mohamed Haj Yousef sostiene que el sentido del oído requiere sólo una dimensión, el de la vista dos dimensiones. Para que surja la imagen en tres dimensiones es necesaria la operación de integración que efectúa la imaginación. Los contenidos de la memoria, para Haj Yousef, poseen en general dos dimensiones, aunque también, en el caso de los sonidos, una sola. Pero cuando la imaginación los integra entre sí y los introduce en el flujo del tiempo se produce la tridimensionalidad. La imagen en volumen, la profundidad o el relieve, en este sentido, surge de la siguiente fórmula: imagen + tiempo. En realidad, se trata de dos imágenes (la corporal y la espiritual) más su integración en el tiempo.

\begin{abstract}
El sentido del oído requiere sólo 1-D, porque la propagación del sonido es recibida por el oído a razón de un bit por vez. La visión, por su parte, requiere 2-D porque cada vez percibimos una imagen que ocupa una superficie. Para concebir $3-D$, sin embargo, necesitamos la imaginación porque el espacio 3-D que concebimos es el resultado de la integración de imágenes 2-D que percibimos a través de un flujo de tiempo. Percibimos 1-D sólo por el oído, y 2-D por la vista, y concebimos 3-D por la imaginación. Por eso nuestros pensamientos o imaginaciones que tenemos en nuestra memoria son de hecho imágenes 2-D (pero también sonidos 1-D) pero al integrarlos en el tiempo concebimos el volumen (Haj Yousef, 2008: 191).
\end{abstract}

Los animales de la especie homo sapiens contemplamos, como en un cine $3 \mathrm{D}$, el relieve de nuestra "naturaleza". Las imágenes proyectadas sobre la pantalla mutan con el tiempo. Cada formación histórica genera su imagen específica (o secuencia de imágenes). La pantalla es una suerte de a priori histórico-antropológico. Hay quienes sueñan con la posibilidad de que algún día el dispositivo se detenga. Caerían entonces los anteojos 3D y veríamos no sólo la ilusión de la tridimensionalidad sino directamente la pantalla blanca, vacía; veríamos el a priori, lo que hizo posible que viéramos, que nos viéramos. Pero al ver la pantalla, y no las imágenes proyectadas en ella, ya no nos veríamos. De todas formas, la pantalla blanca, como el centro de la máquina jesiana, pareciera estarnos por siempre vedado. Así y todo, luego de Nietzsche, sabemos que la pantalla está vacía. Y ese saber, mínimo pero a la vez decisivo, nos vuelve fantasmas no-existentes. No somos por eso humanos, pero tampoco animales ni ángeles. No existimos. El hombre es el único ente que no ex-iste, como existen los animales y los ángeles, los cuerpos y las almas, las cosas y las ideas; el hombre subsiste. ${ }^{26}$ La profundidad de la imagen humana coincide con la superficialidad de la insistencia o de la subsistencia. Es sentido común: todos saben que en el cuerpo humano existe un margen que no coincide con el cuerpo, que no se agota en el
25. Heidegger dedica varias páginas del curso dictado en el semestre invernal de 1929-30, publicado bajo el título Die Grundbegriffe der Metaphysik. Welt-Endlichkeit - Einsamkeit, a discutir la noción de abierto (Offen) en relación a la animalidad. A diferencia de Rilke, para Heidegger sólo el hombre, en la medida en que existe en un mundo, puede ver lo abierto. Sobre el problema de la animalidad en Heidegger, cfr. Calarco (2008: 15-53); Buchanan (2008: 39-114); Agamben (2002: 52-80).
26. Según Alexius Meinong, la metafísica siempre ha pensado como existente o bien a lo físico (en su línea más materialista) o bien a lo psíquico (en su línea más idealista): “Si, como podríamos creer, todo lo que existe en el mundo es o bien psicológico o físico, entonces la metafísica, en tanto concierne a lo psicológico y a lo físico, es la ciencia de la realidad en general" (1904: 37). Sin embargo, el quiasmo en el que esos dos elementos se articulan resulta irreductible a ambos $y$, por lo tanto, no puede decirse que exista; se dirá, más bien, que subsiste. La reducción de todo objeto o relación a el reino de lo existente-actual es denominado por Meinong "prejuicio en favor de la existencia" (cfr. 1904: 11) o "prejuicio en favor de lo actual/real [wirklich]" (1904:24). 
27. Es preciso matizar estas afirmaciones. Cuando decimos que la historia de la metafísica no ha pensado el límite de articulación entre lo sensible y lo inteligible queremos decir que no lo ha pensado, salvo contadas excepciones, en su irreductibilidad, es decir como espaciamiento neutro (ne...uter. ni/ni), como movimiento que suspende la polaridad metafísica tradicional. La imaginación concierne propiamente a este espaciamiento. No sólo constituye el nexo entre lo sensible y lo inteligible sino también su suspensión y su perversión. En este sentido, hemos dicho que la imagen, sensible y a la vez inteligible pero también nisensible $n i$ inteligible, designa el lugar específico de lo humano. No porque este lugar albergue la esencia imperecedera del homo sapiens, sino porque en él se abisma lo humano hasta disolverse por completo. El lugar del hombre, la imagen y consecuentemente la imaginación, es tanto condición de posibilidad como de imposibilidad del homo. De la misma manera, hemos sugerido una equivalencia entre lo sensible y el cuerpo y entre lo inteligible y el alma. Sin embargo, estos términos no son sinónimos; todos ellos aluden, más bien, a regiones ontológicas y epistemológicas diversas pero solapadas. La metafísica occidental tendió a tejer una red de complicidad entre el cuerpo y lo sensible, así como entre el alma y lo inteligible. Lo cual no significa, por supuesto, que la única manera de entender lo sensible y lo inteligible esté determinada por la tradición metafísica. En la nota 30 hemos visto, de hecho, que Emanuele Coccia propone una concepción de lo sensible diversa a la que encontramos en Platón o Descartes. Lo mismo habría que decir de lo inteligible. Nos ha interesado señalar, eso sí, la complicidad que existe entre antropología y metafísica, pero al mismo tiempo mostrar la posibilidad de dislocar todos estos términos y categorías. Creemos que en líneas generales la historia de la metafísica occidental ha pensado la imagen y la imaginación, en el mejor de los casos, como instancias mediadoras entre las dos regiones ontológicas legadas por Platón a la posteridad, pero no ha sido capaz de pensarlas como instancias neutras o punto de suspensión de esa misma ontología. Esta incapacidad, sin duda, responde a cuestiones históricas. En efecto, pensar la imagen y la imaginación en este último sentido hubiese implicado abordar una "entidad", la imagen, y un topos, la imaginación, que, en sentido estricto, no pertenecen más a las categorías de la metafísica de Occidente. En tanto límite conjuntivo, la imaginación permite el pasaje de lo sensible a lo inteligible y viceversa; pero en tanto límite disyuntivo, desactiva la polaridad que lo humano precisamente ha pretendido colmar. Sobre la noción de disyunción, en un

sentido cercano al que le damos aquí, cfr. Ludueña Romandini (2016: 265-271). cuerpo, un exceso del propio cuerpo, así como en el alma humana hay un margen que no coincide con el alma, que no se agota en el alma, un exceso de la propia alma. Durante siglos se predicó la existencia del cuerpo o del alma o del compuesto de ambos elementos, pero nunca se pensó, o no se pensó en profundidad, su límite de articulación, el espesor vacío o la fractura tenue entre ambos. Lo que sí es seguro es que a lo largo de los siglos, de manera velada o subrepticia, los hombres identificaron ese margen o límite como el lugar propio de las imágenes y de la imaginación. Las imágenes fueron así consignadas a este límite que es por necesidad el límite del Ser, al menos tal como ha sido concebido a lo largo de las líneas dominantes de la tradición occidental. Lo curioso es que este límite ontológico, esta fractura sutil entre lo sensible y lo inteligible, este no-ya sensible y no-aún inteligible es precisamente lo humano. ${ }^{27}$ Pero esta afirmación, como hemos mostrado, no significa la reivindicación de una esencia que ubicara al hombre en una posición excepcional respecto al resto de los entes. No se trata de un privilegio ontológico, no se trata de resucitar los humanismos tradicionales bajo cualquiera de sus formas. Se trata de mostrar que lo humano, lo que los hombres han pensado a lo largo de los siglos como su "verdad" más esencial y su secreto más inalienable, no es sino una imagen. Y si el estatuto de la imagen pone en cuestión la dualidad sensible/inteligible o cuerpo/alma, lo humano debe ser pensado, en tanto imagen, con categorías diversas a estas polaridades metafísicas. De nuevo: no es que la imagen ocupe ese lugar central por ser humana, sino que lo humano ocupa ese lugar central por ser una imagen. Ello no significa, sin embargo, que lo humano designe un tercer género del Ser, aunque sería ya una posición más interesante que pensar al hombre como un mero compuesto de alma y cuerpo, pero sí significa que hay una frontera o más bien una región, prácticamente inextensa y extremadamente frágil, en la que tanto el cuerpo como el alma se exceden a sí mismos, una suerte de solapamiento que no es, estrictamente hablando, ni alma ni cuerpo pero que tampoco es otra cosa. Llamamos a esta entidad imagen.

\section{Conclusión}

A lo largo de este artículo, hemos explicado los aspectos fundamentales de la máquina óptica. Según lo desarrollado hasta aquí, podemos definir a la máquina óptica como el dispositivo histórico que produce, a partir de la integración de la imagen proveniente del ojo del alma y de la imagen proveniente del ojo del cuerpo, una imagen tridimensional de lo humano. Para comprender en profundidad el funcionamiento de la máquina hemos analizado sus partes constituyentes y al mismo tiempo su interacción. Cada apartado de este escrito, por eso mismo, ha estado consagrado a explicar un aspecto específico de su estructura formal. En un sentido general, hemos individuado los siguientes aspectos estructurales:

1) Es una máquina estereoscópica. El estereoscopio es un dispositivo óptico que produce la ilusión de una escena u objeto tri-dimensional a partir de la integración de dos imágenes planas diferentes, las cuales son vistas a través del aparato de tal modo que cada ojo ve sólo una de las dos imágenes. Cuando se observan las dos imágenes a través de un visor especial, el par de imágenes bi-dimensionales se funden en una única imagen tri-dimensional.

2) La imagen generada por la máquina óptica es necesariamente diplópica, es decir doble o desdoblada. Cuando el funcionamiento estereoscópico de la máquina óptica resuelve las dos imágenes dispares en una única imagen tridimensional, la cual se produce a medio camino de las dos imágenes monoculares, éstas no desaparecen, sino que sobreviven o subsisten, más bien, como fantasmas o restos espectrales. La máquina óptica intenta corregir esta diplopía produciendo una imagen haplópica tridimensional. 
3) Las dos imágenes provenientes de cada ojo, el del alma y el del cuerpo, se integran o resuelven en el quiasma óptico. Nosotros hemos identificado al quiasma, retomando algunas ideas de Francisco de Aguilón entre otros, con la imaginación. A lo largo de la historia de la metafísica la imaginación ha sido precisamente el quiasmo o el pliegue, la superficie de contacto, en la que se han articulado y a la vez distinguido los dos grandes planos del Ser tal como ha sido pensado en Occidente: lo sensible y lo inteligible, la materia y el espíritu, el cuerpo y el alma, etc. Por eso mismo, si la máquina óptica se caracteriza por articular la imagen del ojo del cuerpo con la del ojo del alma, y si esa función le ha pertenecido específicamente a la imaginación, entonces la máquina óptica es un dispositivo imaginante, es decir generador o productor de imágenes del hombre.

4) Lo humano es el efecto de tridimensionalidad o profundidad, la estereopsis generada por la máquina óptica a partir de la integración de las imágenes bidimensionales provenientes de cada ojo. Cada formación histórica tiene su modo de solapar las miradas y, en consecuencia, su modo de generar una cierta profundidad.

La tesis más importante que se desprende de este análisis de los diversos aspectos de la máquina óptica es que lo humano es una imagen. Esto no es una mera metáfora: el estatuto ontológico de lo humano es el de una imagen. El cuerpo fuera de sí, en un afuera que no se confunde con el alma; el alma fuera de sí, en un afuera que no se confunde con el cuerpo: eso es la imagen. La insuficiencia de la metafísica, en su sentido histórico dominante, insuficiencia que consiste en el prejuicio en favor de lo actual o de lo existente que hemos mencionado, se caracteriza por haber pensado siempre el afuera del cuerpo como alma y el afuera del alma como cuerpo. Lo cual significa que no ha pensado, sensu stricto, la imagen. O cuando lo ha hecho, ha sido siempre en sus orillas y de forma más o menos subterránea. Esto es así porque las imágenes poseen un ser menor o débil, difícil de aprehender con las categorías dicotómicas tradicionales. El hombre, en suma, es una imagen, un fantasma producido por un dispositivo histórico que decide, cada vez, los límites que lo separan, y al mismo tiempo lo unen, con lo natural y lo sobrenatural, lo animal y lo divino.

20 Recordemos que para Aristóteles la imaginación [qavtaoía] no coincide ni con la sensación, ni con la opinión, ni con la ciencia ni con la inteligencia (cfr. De anima, 428a). Sobre la fantasía en Aristóteles, cfr. Schofield (1995: 250-279). Más recientemente Emanuele Coccia, tanto en La transparenza delle immagini (2005) cuanto en La vita sensibile (2010), ha reflexionado ampliamente sobre la noción de "imagen" y de "imaginación", sobre todo - aunque no sólo - en la cultura medieval de tradición aristotélica. En La vita sensibile, por ejemplo, Coccia sostiene que el ser de las imágenes no se confunde ni con el ser de los objetos ni con el ser de los sujetos. En este sentido, designa un afuera que ha subsistido, como los sueños, en los márgenes de la tradición occidental: "Se podría decir que la imagen es el afuera absoluto, una especie de hiper-espacio, aquello que se mantiene fuera del alma y fuera de los cuerpos" (2010: 24). Este afuera absoluto, cuya fragilidad ontológica requiere una hiper-topografía, esta suerte de hiper-espacio del que habla Coccia es el espacio tridimensional de la imaginación. Coccia lo denomina, sin más, sensible. No hay que creer, sin embargo, que se trata del sensible platónico, es decir del sensible entendido como mera materia corpórea. Lo sensible, tal como Coccia lo entiende, designa el medio específico de las imágenes que, en cuanto tales, no pertenecen ni al registro de lo objetivo ni al registro de lo subjetivo. "Lo sensible - explica Coccia - es el ser de las formas cuando están en el exterior, exiliadas del propio lugar" (2010: 25). La imagen no es más que este exilio, en un doble sentido: respecto al cuerpo y respecto al alma. La fantasía o la imaginación, por su parte, es la facultad capaz de conectar, por un lado, lo sensible con lo inteligible, y, por otro, capaz de suspender la polaridad metafísica y abrir un tertium específico e irreductible a ambos términos. Sobre la concepción averroísta de la imaginación y de las imágenes, cfr. Coccia (2005: 144-178). (En página 188.) 


\section{Bibliografía}

"Agamben, G. (2002). L'aperto. L' uomo e l'animale. Torino: Bollati Boringhieri.

" Agamben, G. (2007). Ninfe. Torino: Bollati Boringhieri.

"Aguilón, F. de (1633). Opticorum Libri Sex philosophis juxta ac mathematicis utiles, Antverplae, Ex Officina Plantiniana.

» Aristóteles (1978). Acerca del alma (Traducido por Tomás Calvo Martínez). Madrid: Gredos.

» Barth, R. (1977). The Symbolic Imagination. Coleridge and the Romantic Tradition. New Jersey: Princeton University Press.

» Bataille, G. (1973). L'expérience intérieure. En Oeuvres completes, tomo V. Paris: Gallimard.

» Blake, W. (1988). The Complete Poetry\& Prose of William Blake. Erdman, D. V. (ed.). New York : Anchor Books.

" Brewster, D. (1856). The Stereoscope. Its History, Theory, and Construction. Londres: John Murray.

" Buchanan, B. (2008). Onto-Ethologies. The Animal Environments of Uexküll, Heidegger, Merleau-Ponty and Deleuze. New York: S.U.N.Y. Press.

" Bundy, M. (1922). Plato's View of the Imagination. Studies in Philology, Vol. 19, No. 4.

" Calarco, M. (2008). Zoographies. The Question of the Animal from Heidegger to Derrida. New York: Columbia University Press.

"Coccia, E. (2005). La trasparenza delle immagini. Averroè e l'averroismo. Milano: Bruno Mondadori.

» Coccia, E. (2010). A vida sensivel (Traducido por Diego Cervelin). Florianopolis: Editora Cultura e Barbárie.

»Descartes, R. (1986). CEuvres complètes, 12 vols. Adam, Ch. \&Tannery, P. (Eds.). Paris: Vrin.

"Engell, J. (1981). The Creative Imagination. Enlightenment to Romanticism. Cambridge - Londres: Harvard University Press.

"Fludd, R. (1619). Utriusque Cosmi maioris salicet et minoris metaphysica physica, atque technical Historia, Oppenhemij Impensis Iohannis Theodori de Brÿ, Tome II.

"Foucault, M. (1975). Surveiller et punir. Naissance de la prison. Paris: Gallimard.

"Galeno, C. (1978). De usu partium corporis humani. En Opere scelte (a cura di Garofalo, I. et Vegetti, M). Torino: Unione Tipografico-Editrice Torinese.

» Heidegger, M. (1997). Platons Lehre von der Wahrheit. Frankfurt am Main: Vittorio Klostermann.

» Howard, I. P. et Rogers B. J. (1995). Binocular Vision and Stereopsis. New York Oxford: Oxford University Press.

» Jesi, F. (1977). La festa. Antropologia, etnologia, folklore. Torino: Rosenberg \& Sellier.

"Jesi, F. (1980). Mito. Milano: Mondadori. 
" Kearney, R. (2003). The Wake of Imagination. Toward a postmodern culture. Londres: Routledge.

» Konstan, D. (2013). Biblical Beauty: Hebrew, Greek, and Latin. En Hodge, C. J. et al., "The One Who Sows Bountifully": Essays in Honor of Stanley K. Stowers, Society of Biblical Literature.

» Ludueña Romandini, F. (2016). Principios de espectrología. La comunidad de los espectros II. Buenos Aires : Miño y Dávila.

" McNiece, G. (1992). The Knowledge that Endures: Coleridge, German Philosophy, and the Logic of Romantic Thought. New York: Palgrave MacMillan.

» Meillassoux, Q. (2006). Après la finitude. Essai sur la nécessité de la contingence. Paris: Éditions du Seuil.

» Meinong, A. (1904). Untersuchungen zur Gegenstandstheorie und Psychologie. Leipzig, Verlag von Johann Ambrosius Barth.

"Panum, P. L. (1858). Physiologische Untersuchungen uber das Sehen mit zwei Augen. Kiel: Schwerssche Buchhandlung.

» Platón (1988). República. En Diálogos vol. IV (Traducido por Conrado Eggers Lan, Madrid: Gredos.

» Pons Moreno, A. M. et Martínez Verdú, F. M. (2004). Fundamentos de Visión Binocular. Valencia: Universitat de València.

"Prósperi, G. (2015). La máquina elíptica de Giorgio Agamben. Profanaçoes, vol. 2, Brasil, 62-83. Recuperado de [http://www.periodicos.unc.br/index.php/prof/article/view/945/580].

" Raynaud, D. (2003). Ibn al-Haytham sur la vision binoculaire: un precurseur de l'optique physiologique. En Arabic Sciences and Philosophy (pp. 79-99). Cambridge: Cambridge University Press, 13.

" Raynaud, D. (2016). Studies on Binocular Vision. Optics, Vision and Perspective from the Thirteenth to the Seventeenth Centuries. Grenoble: Springer.

» Schofield, M. (1995). Aristotle on the Imagination. En Rorty, O. et Nussbaum, M. (Eds.). Essays on Aristotle's De Anima. Oxford: Clarendon Press.

" Simondon, G. (2013). L'individuation à la lumière des notions de forme et d'information. Grenoble: Éditions Jérôme Millon.

»Vernant, J.-P. (2007). Oeuvres. Religion, Rationalités, Politique, Tome I. Paris: Éditions du Seuil.

»Wade, N.J. et Ngo, T. T. (2013). Early views on binocular rivalry. En Miller, S. M. (Ed.). The Constitution of Visual Consciousness: Lessons from Binocular Rivalry. Amsterdam - Philadelphia: John Benjamins Publishing Company.

"Wheatstone, Ch. (1838). Contributions to the Physiology of Vision. On Some Remarkable, and Hitherto Unobserved, Phenomena of Binocular Vision. Philosophical Transactions of the Royal Society of London, vol. 128, 1 de enero.

» Yousef, M. H. (2008). Ibn 'Arabî.Time and Cosmology. Londres-New York: Routledge.

»Ziggelaar, A. S. J. (2011). François De Aguilón's Opticorum Libri Sex-First Description of the Horopter, the Area of Single Vision, in 1613. En Strabismus, 19(4), pp. 166-167.

"Ziggelaar, A. S. J. (2012). The Contents Of The Opticorum Libri Sex. En Strabismus, 20(2), pp. 84-104. 
